For The Oxford Handbook of Value Theory, eds., Iwao Hirose and Jonas Olson, Oxford: Oxford University Press

\begin{abstract}
:
This chapter begins by describing the phenomena of incommensurability and incomparability, how they are related, and why they are important. Since incomparability is the more significant phenomenon, the remainder of the chapter undertakes a more detailed investigation of incomparability. It gives an account of what incomparability is, investigates the relation between the incomparability of values and the incomparability of alternatives for choice, distinguishes incomparability from the related phenomena of parity, indeterminacy and noncomparability, and, finally, defends a view about practical justification that vindicates the importance of incomparability for practical reason.
\end{abstract}

Keywords: INCOMMENSURABILITY, INCOMPARABILITY, VALUE, PRACTICAL REASON, CHOICE, SCALE OF VALUE, MEASUREMENT OF VALUE, PARITY, INDETERMINACY, NONCOMPARABILITY, RATIONAL AGENCY

Ruth Chang is professor of philosophy at Rutgers University, New Brunswick.

\title{
Value Incomparability and Incommensurability ${ }^{1}$ Ruth Chang
}

What is incomparability? What is incommensurability? How do they relate? And why are they important?

As we will see, incomparability, and not incommensurability, is the more important phenomenon, and so that will be our main focus here. This chapter examines what incomparability is and the relation between the incomparability of values and the incomparability of alternatives for choice $(\S 2)$, differentiates incomparability from the related phenomena of parity, indeterminacy, and noncomparability ( $\$ 3)$, and defends a view about practical justification that vindicates the importance of incomparability for understanding rational choice ( $\$ 4)$. But first we turn to incommensurability $(\S 1)$. What is it, what is its significance, and how it is related to incomparability?

\section{Incommensurability and Incomparability}

We start with a gloss of each phenomena. Two items are incommensurable just in case they cannot be put on the same scale of units of value, that is, there is no cardinal unit of measure that can represent the value of both items. Two items are

${ }^{1}$ Thanks Iwao Hirose and Jonas Olson for helpful editorial comments. 
incomparable just in case they fail to stand in an evaluative comparative relation, such as being better than or worse than or equally as good as the other.

Incomparability is thought to be of greatest philosophical significance when holding between alternatives for choice. Suppose you are faced with a choice between two incomparable options, say, spending your annual bonus on a new car or donating the money to Oxfam. If the alternatives cannot be compared with respect to what matters in the choice between them, it seems that there can be no justified choice between them.

As many philosophers believe, you're justified in choosing one alternative over another only if it is better or as good as the other, and incomparability holds when it's false that they stand in any such comparative relation. Incomparability among alternatives, then, leads to a breakdown in practical reason. If incomparability is widespread, then what we do in most choice situations falls outside the scope of practical reason. This in turn has upshots for our understanding of paradigmatic human agency: instead of being Enlightenment creatures who act according to the dictates of reason, we lead our lives without the guidance of reason.

Incommensurability, by contrast, is thought to be of most philosophical significance when holding, not between alternatives for choice, but between abstract values. ${ }^{2}$ (Values, as I am understanding them, include any evaluative abstracta, including obligations, rights, duties, utility, excellences and so on, and are not limited to evaluative criteria, like pleasure, that can be aggregated by a cardinal unit of measure. $^{3}$ ) If two values cannot be measured by a cardinal unit, they are incommensurable. This use of 'incommensurability' derives from the Greek term 'asummetros' used by Aristotle to refer to the Pythagorean discovery that the lengths of the diagonal and side of a unit square -1 and $\sqrt{2}$ - could not be placed on a single scale of numbers (von Fritz 1970; Heath 1921). Because the Pythagoreans thought that all numbers were rational, they believed that $\sqrt{2}$ could not be put on the same scale as 1 . Today, of course, we have the real numbers, which include both rational and irrational numbers, and so the Pythagoreans did not have a genuine case of incommensurability. Nevertheless, they gave birth to the idea that items could lack a shared cardinal measure.

\footnotetext{
2 For a survey of different phenomena that sometimes go under the label 'the incommensurability of values' and their philosophical significance, see Chang $2009 \mathrm{~b}$ and Hsieh 2008.

3 It is unfortunate that the term 'values' has, at least in some quarters, been co-opted to refer only to evaluative abstracta that admit of cardinally significant representation, ruling out, it is supposed, 'deontic' considerations like duties. But the ordinary notion of 'values' is much broader and includes considerations like duties, rights, and excellences, like scientific achievement, which may not be so represented. See also Scanlon 1998: ch. 2 for a similar appeal to a broad, 'ordinary' notion of values. Compare Zimmerman, this volume.
} 
The importance of the incommensurability of values lies primarily in axiology, not in the philosophy of practical reason. If values are incommensurable, then values cannot be represented by cardinally significant real numbers. There is no cardinal unit - such as dollars - in terms of which we can measure pleasure and scientific achievement. Any hope of being able to mathematically model values on the reals, as we might model quantities of mass or length, must be abandoned. And so certain crude ethical theories, such as traditional forms of utilitarianism that presuppose values can be cardinally represented by utiles, must also be rejected. But since no plausible ethical theory essentially relies on the commensurability of values, the importance of value incommensurability is limited.

There is a derivative upshot for practical reason. If the values that matter in the choice between buying a new car and donating to Oxfam - say, utility and fulfilling moral obligations - are incommensurable, then it would be a mistake to model the rationality of the choice by assuming that rationality is a matter of maximizing some cardinally significant unit of value. Thus the incommensurability of values undermines expected utility theory and cost benefit analysis, which presuppose the cardinal measurement of the value or the preferability of options. At best, these approaches must be understood as crude heuristics for rational choice. But since many thinkers have already rejected these models as problematic on other grounds, the importance of the incommensurability of values for practical reason is also limited. 4

How do incommensurability - the failure to be measurable by a shared cardinal unit of value - and incomparability - the failure to be comparable - relate? Some philosophers have mistakenly assumed that the incommensurability of values entails the incomparability of those values or their bearers. Some, for example, have noted that if values cannot be put on a "single scale" on which they can be "measured, added, and balanced", then alternatives bearing them could not be compared, and rational choice between them would have to proceed not by a comparison of their merits but by some other means (e.g.. Hart 1961; Anderson 1997: 55ff; D'Agostino 2003), such as phronesis, that is, a judgment of practical wisdom (Nagel 1979: 131). But incommensurability does not entail incomparability - whether of values or their bearers.

Consider an example. Suppose, as is plausible, that there is no cardinally significant unit of measurement by which we can evaluate both the abstract values of justice and mercy - justice and mercy are incommensurable. It does not follow that justice is not better than mercy with respect to promoting a secure and legitimate polis or that mercy is not better than justice with respect to being godly. Values may be comparable even if they are incommensurable. Nor does it follow that bearers of

${ }^{4}$ Other reasons to reject such views point to the nature of intelligent deliberation (Richardson 2000) and the possibility of organic unities among values (Carlson this volume). See Adler this volume for a review of different forms of cost benefit analysis. 
those values cannot be compared. A state policy of proportional punishment is better than a meter maid's merciful act of not writing someone a parking ticket with respect to achieving political legitimacy for the state. Bearers of value may be comparable even if the values they bear are incommensurable.

Nor does the incommensurability of bearers of value entail their incomparability. Even if there is no cardinal unit, such as a utile or a dollar, in terms of which the value of buying a new car and of donating the money to Oxfam can be measured, it might nevertheless be true that, with respect to moral goodness, donating to Oxfam is better. ${ }^{5}$

While incommensurability does not entail incomparability, incomparability entails incommensurability. If there is no comparative relation that holds between two items, a fortiori, there is no cardinal unit of measurement by which the two might be compared. Being commensurable is simply one way in which items might be comparable, and so if items are incomparable, they are incommensurable. Thus while incommensurability does not entail incomparability, commensurability entails comparability, both for value bearers and for abstract values themselves.

It is unfortunate that 'incommensurability' is sometimes used as a synonym for 'incomparability' (Raz 1986; Anderson 1993), since, as we've seen, incommensurability does not entail incomparability let alone reduce to it. The reverse is not true; no one has, to my knowledge, used 'incomparability' to refer to incommensurability, although, as we have seen, the incomparability of items entails their incommensurability. An explanation of this usage is that incomparability - the failure of comparability - and not incommensurability - the failure of cardinal measurability - is the more philosophically significant phenomenon.

\section{What is Incomparability?}

We glossed incomparability as the failure of comparability. Here is a precise definition of incomparability.

Incomparability (def): Two items are incomparable if it is false that any positive, basic, binary value relation holds between them with respect to a covering consideration, ' $\mathrm{V}$ '.

This needs unpacking. A value relation is positive if it represents how items relate rather than how they fail to relate. So, for example, ' $\mathrm{x}$ is better than $\mathrm{y}$ ' says something about how $\mathrm{x}$ stands to $\mathrm{y}$ while ' $\mathrm{x}$ is not better than $\mathrm{y}$ ' says only how $\mathrm{x}$ does not stand to $y$. 'Is better than' is thus a positive value relation while 'is not better than' is not.

\footnotetext{
${ }^{5}$ See Schmidtz this volume for other examples of ranking incommensurable items.
} 
A set of value relations is basic if it exhausts the conceptual space of comparability between two items with respect to $\mathrm{V}$. A value relation is 'basic' if it is a member of a basic set. So, for example, ' $x$ is better than $y$ ' belongs to a basic set, while ' $x$ is better than y but only slightly worse than z' does not. Many thinkers have assumed that 'better than', 'worse than', and 'equally good' form a basic set of value relations, and thus that if these relations fail to hold of two items with respect to $V$, the items are incomparable with respect to V. Call this the 'Trichotomy Thesis'. We will be returning to this thesis later.

A value relation is binary if it relates exactly two items with respect to V. So, for instance, ' $\mathrm{x}$ is much better than $\mathrm{y}$ with respect to $\mathrm{V}$ than $\mathrm{z}$ is' would not be binary while ' $x$ is better than $y$ with respect to $V$ ' would be.

Incomparability is the failure of any positive, basic, binary value relation to hold between two items with respect to a 'covering consideration', $V$. ' $V$ ' is a variable for either a single consideration or multiple considerations - and here we will assume that a value or values play this role. If a comparison proceeds with respect to multiple values, v1, v2, v3, and so on, there is the question of how these values relate to one another. This is an important and controversial question at the intersection of axiology and the philosophy of practical reason that we can't address here. ${ }^{6}$ For our purposes we will simply assume that v1, v2, v3... can stand in any relation, including mere conjunction. So if $\mathrm{x}$ and $\mathrm{y}$ are incomparable, they cannot be compared - with respect to some value or values, V. Later we'll see why V is aptly called a 'covering' consideration.

To see why claims of incomparability must proceed relative to a covering consideration, consider claims of comparability. Two items are never comparable, simpliciter; they are always comparable in some respect or respects. Chalk is comparable with cheese in some respects - cheese tastes better. Apples are comparable with oranges in some respects - apples are worse with respect to preventing scurvy. Being comparable is a matter of there being a positive, basic, binary value relation that holds between items with respect to $V$. Saying that two items are comparable, simplicter, expresses an incomplete thought - comparable in what respect or respects? ${ }^{7}$ Note that the same goes for nonevaluative comparisons. A stick can't be greater than a billiard ball, simpliciter; it must be greater in some respect, such as mass or length.

${ }^{6}$ For a defense of the idea that $\mathrm{V}$ represents a unity, see Chang 2004b; for debate about this idea in the context of conflicts between morality and prudence, see e.g., Chang 2004a, Raz 1999; Bader (this volume); Richardson 2004.

${ }^{7}$ It would be a mistake to understand comparability as obtaining between two items just in case there is a single comparison that holds between them with respect to some or other $\mathrm{V}$ since this would make comparability a trivial phenomenon. Correspondingly, it would be a mistake to understand incomparability as holding so long as there is no $\mathrm{V}$ in terms of which the two items could be compared. I address this phenomenon, which is not of much philosophical significance, in the text below. 
As the negation of claims of comparability, claims of incomparability must have the same logical form. Two items are never incomparable, simpliciter, but only incomparable with respect to $\mathrm{V}$. As we will see, failure to appreciate the fact that incomparability must proceed with respect to a covering consideration has led some philosophers to conflate incomparability with other, quite distinct, phenomena.

\section{a. $\underline{\text { Of Values }}$}

Incomparability is the failure of any positive, basic, binary relation to hold between two items with respect to $\mathrm{V}$. If the items being compared are abstract values, then the claim of incomparability is the claim that one value is incomparable with another value with respect to some $\mathrm{V}$.

But what does it mean to say that one abstract value, such as happiness, is incomparable with another abstract value, such as gustatory pleasure, with respect to an abstract value, $\mathrm{V}$, such as individual well-being?

Again, we can look to comparability for help. If one value is better than another with respect to $\mathrm{V}$, it makes a greater contribution to $\mathrm{V} .^{8}$ Or, equivalently for our purposes, having the one value makes a greater contribution to having (more of/a significant manifestation of) $\mathrm{V}$ than does having the other value. So if happiness is better than gustatory pleasure with respect to individual well-being, then having happiness goes further toward - makes a more significant contribution to - having a good life than does having gustatory pleasure. Crucially, this is to be understood as a purely abstract claim and not one about any particular instantiations of happiness or of gustatory pleasure.

We can go further. Suppose that happiness is better than gustatory pleasure with respect to well-being, that is, being happy contributes more to one's well-being than does having gustatory pleasure. How exactly are we to understand this claim? After all, not every instantiation of happiness contributes more to one's well-being than every instantiation of gustatory pleasure. The once-in-a-lifetime pleasure of a custom-prepared five-course meal at Daniel might, arguably, contribute more to one's well-being than the fleeting sense of happiness one has when the sun is shining and all seems well with the world. At least we want to leave open that possibility.

Comparisons between values in terms of their contribution to some $V$ are themselves explained in terms of other comparative facts - facts about how particular instantiations of those values comparatively relate with respect to $\mathrm{V}$

\footnotetext{
${ }^{8}$ An important issue here is whether the contribution must be constitutive or whether it may be instrumental or, indeed, some other way in which one value may 'contribute' to another. I leave these interesting, somewhat technical, issues aside.
} 
across sets of possible background facts. ${ }^{9}$ Happiness can be multiply instantiated there is the happiness of achieving a life-long goal, the happiness of winning the lottery, the happiness of feeling the sun on your face after spending all day working in the office. (If these examples strike you as problematic, substitute your own). Comparisons of abstract values are explained in terms of comparisons of the multitude of instantiations of them with respect to $V$ across a multitude of possible background facts.

A toy illustration will help. Suppose God wishes to determine the comparative contribution of happiness and gustatory pleasure to individual well-being. He starts by considering the well-being of an arbitrary individual - let's call her 'Mary'. Mary exists in many possible worlds. God picks out one possible world and asks, 'Which would constitute a greater contribution to Mary's well-being in that world - adding to her life the happiness of a good romantic relationship or adding to her life the gustatory pleasure of her favorite dessert?' He concludes that the happiness would contribute more. He then moves onto the other instantiations of happiness and gustatory pleasure. For instance, he asks 'Which would constitute a greater contribution to Mary's well-being - adding to her life the happiness of getting birthday greetings from a distant acquaintance or adding to her life the gustatory pleasure of the best meal she will have in her lifetime? He concludes that the gustatory pleasure would contribute more. He carries on in this fashion until he has gone through all the possible instantiations of happiness and gustatory pleasure, determining which instantiation makes the greatest contribution to Mary's wellbeing in the given possible world. After taking a coffee break, he then goes on to repeat the process for every other possible world. At the end of day, he has a set of comparative facts about every possible instantiation of the abstract values in question as to their relative contribution to Mary's individual well-being across every possible circumstance. (Since Mary is, by hypothesis, an arbitrary individual, he only has to ask these questions about Mary, but of course there will be variations in answer across actual individuals in the same circumstances). These facts are the 'inputs' to the determination of the comparative relation between the abstract values of happiness and gustatory pleasure with respect to their contribution to making a good life. For convenience, we might call the determination of the comparative relation between abstract values a 'value comparison function.'

Now we don't have much of a handle on what this value comparison function could be (not to mention how to determine its inputs). But we can posit a general feature a plausible function must have that has significance for our thinking about the relation between the incomparability of values and the incomparability of value bearers.

9 This formulation allows the possibility that background facts make no difference to how the instantiations relate if comparisons of value instantiations with respect to $\mathrm{V}$ are not background-fact-sensitive. 
Possible value comparison functions might be arrayed very roughly along a spectrum; at one end are the 'super-permissive' functions according to which any incomparability among instantiations in any possible world yields the incomparability of the values themselves, while at the other end are the 'superrestrictive' according to which all instantiations must be incomparable in order for the values themselves to be incomparable. ${ }^{10}$ Super-restrictive functions are clearly implausible; surely values could be incomparable even if some of their instantiations were comparable. All we have to do is think of candidate cases of incomparable values and note that a very good or 'notable' instantiation of one of them is plausibly comparable with a very bad or 'nominal' instantiation of the other in at least one possible world. Moreover, as we'll see shortly, there is a further formal constraint on comparisons - that ' $\mathrm{V}$ ' 'cover' the items being compared - which underwrites the plausibility that there will always be some instantiation of a value that is comparable with some instantiation of another value with respect to contribution to $\mathrm{V}$. If this is right, then we can proceed on the fairly secure assumption that even if two abstract values are incomparable with respect to $\mathrm{V}$, some of their instantiations may be comparable with respect to $\mathrm{V}$.

This in turn has an important implication for the relation between the incomparability of values and the incomparability of their bearers. Although happiness may be incomparable with gustatory pleasure with respect to individual well-being, the happiness of achieving a worthwhile life-long goal might well be comparable with the gustatory pleasure of a lukewarm cup of coffee with respect to contribution to individual well-being in at least some possible worlds. And although equality may be incomparable with fairness with respect to justice, particular instantiations of equality may be comparable with particular instantiations of fairness in the actual world, and so policies between which the US Congress has to choose that manifest those particular comparable instantiations may nevertheless be comparable with respect to justice. The upshot is that investigation of the incomparability of alternatives for choice can proceed independently of investigation of the incomparability of values. Progress in understanding the incomparability of alternatives for choice and its significance for practical reason is thus not held hostage to progress in the rather more difficult problem of understanding the incomparability of values.

Sometimes philosophers misleadingly speak of the 'incomparability' (or 'incommensurability') of values when what they have in mind is not their incomparability but their normative irreducibility. A value is normatively irreducible if there is no other value in terms of which it can be explained or accounted for. Values might come in different 'types', where types are individuated by some formal or substantive feature that precludes different types of value from being contributors to some value. Perhaps some values are necessarily relativized to

10 I say roughly because some might think that incomparability among values does not require any incomparability as an input, a possibility that does not fit neatly on the mooted spectrum. I leave this possibility aside. 
an individual - they are 'personal values' while others are 'impersonal' and not so relativized (Ronnow-Rasmussen 2011) and so personal and impersonal values cannot be understood as contributors to some common value. Or perhaps agentrelative values are, normatively speaking, irreducibly distinct from agent-neutral values and thus do not contribute to any common value. Or, as some have argued, moral values are normatively irreducible and distinct from prudential values (Copp 1997), or utility is irreducibly distinct from obligation (Nagel 1979: ch. 9).

However, the normative irreducibility of values should not be confused with their incomparability. The confusion arises because the covering consideration requirement has been overlooked: comparability and incomparability must proceed relative to some $\mathrm{V}$. Normative irreducibility holds of two values when there is no $\mathrm{V}$ to which the values contribute - those values cannot be accounted for in terms of their contribution to V. Incomparability holds when comparison between the two values with respect to $\mathrm{V}$ fails. As we will see later, if two values are normatively irreducibly distinct, then they may be noncomparable with respect to each and every value but if noncomparable, then they are neither comparable nor incomparable with respect to those values.

\section{b. Of bearers/alternatives for choice}

Two value bearers are incomparable with respect to $\mathrm{V}$ just in case there is no positive, basic, binary relation that holds between them with respect to $\mathrm{V}$.

Just as there is a value comparison function that determines whether values are comparable, there is a value bearer comparison function that determines the comparability or incomparability of bearers of value. The inputs of that function are comparisons of the instantiations of values manifested by each value bearer against a set of possible circumstances. Take, for example, two paintings, say da Vinci's $L a$ Gioconda and Picasso's Guernica. Suppose we attempt to compare them with respect to beauty. Each painting bears beauty by manifesting particular instantiations of beauty. Our value bearer comparison function takes each comparative fact about how the instantiations of beauty manifested by each painting compare with respect to their contribution to the abstract value of beauty in each possible world - that is, how comparatively beautiful they are in each possible world - and delivers as an output an abstract comparative fact about how beautiful the two paintings are across all possible worlds.

But many - perhaps all - abstract comparative facts about value bearers across all possible worlds are not properly the subject of philosophical investigation. This is because, while declarations that La Gioconda is more beautiful than Guernica in the abstract across all possible worlds may be appropriate at a certain kinds of overintellectual dinner parties, they are silly and pointless (Anderson 1993; 1997). A comparison of the beauty of two paintings does have significance, however, when it is relativized to the actual world. Such comparisons are important when the alternatives are options for choice in the actual world, for example, when you are a 
museum curator deciding which of two paintings to include in an exhibition or a home-owner trying to decide which of two reproductions to hang on your living room wall. In thinking about the incomparability of bearers of value, then, we should focus our attention on bearers of value that are alternatives for choice in a choice situation in the actual world.

\section{What Incomparability is not}

\section{a. Parity}

A general question about incomparability concerns which relations constitute the basic set of value relations that exhaust the conceptual space of comparability between two items with respect to V. Most philosophers have assumed the Trichotomy Thesis, the claim that the trichotomy of relations, 'better than', 'worse than', and 'equally good' (or an equivalent set) form a basic set of value relations; if none of the trichotomy holds between two items with respect to $\mathrm{V}$, it follows that they are incomparable with respect to $\mathrm{V}$. Indeed, many thinkers have defined incomparability as the failure of these three relations to hold.

This is a mistake. Defining incomparability as the failure of the standard trichotomy of relations to hold builds into the concept of incomparability a substantive assumption about which relations exhaust the conceptual space of comparability between two items that is open to debate. And this substantive assumption is no part of the ordinary notion of incomparability.

Consider the following thought experiment. Suppose you are a trichotomist, believing that 'better than', 'worse than' and 'equally good' exhaust the conceptual space of comparability between two items with respect to V. I, however, am a dichotomist, believing that 'better than' and 'worse than' exhaust the conceptual space of comparability between two items with respect to V. You present me with two qualitatively identical bowls of ice cream and ask me to compare them with respect to deliciousness. As a dichotomist, I confidently conclude that they are incomparable with respect to deliciousness; after all, they taste the same to me and since one doesn't taste better than the other, the two are incomparable in tastiness. As a trichotomist, you insist that if they taste the same to me, they are equally good with respect to tastiness. But I don't recognize this relation of being 'equally good'; as I good dichotomist, I maintain that if one is neither better nor worse than the other, they cannot be compared.

This disagreement might simply be verbal; I might simply use 'incomparable' to mean 'neither better nor worse'. But it might instead be substantive. I might have overlooked a possible basic relation of comparability, in which case you will give me substantive arguments that suggest I have. Those arguments might draw upon a shared understanding of comparability and incomparability according to which it is an open question which relations exhaust the conceptual space of comparability between two items. You might appeal to the idea of a positive fact that gives a 
relation that holds between two items in contrast to a negative fact that gives a relation that does not hold between two items and point out that being 'equally good' is more like being 'better than' than being incomparable, that is, not related by any positive fact. On the basis of this shared understanding of comparability, you might give me arguments for the existence of things being equally good. You might draw an analogy with nonevaluative comparisons, and point out that just as two sticks can be of equal length, they can be of equal value with respect to V. You might show what philosophical work the relation of being 'equally good', as opposed to being incomparable, can do in practical reason. Or you might show how related concepts, such as commensurability support there being a relation of 'equally good'. One way two items can be commensurable is by being measured by the same number of cardinal units of value. Since commensurability entails comparability, this way of being commensurable entails a way of being comparable. In short, if we share a concept of comparability that does not have a set of basic value relations built into it, you can, in principle, convince me that there are three, not two, basic relations of comparability.

Our ordinary concept of comparability - and correspondingly of incomparability leaves open which relations exhaust the conceptual space of comparability between two items with respect to a V. It thus leaves open the possibility that there is a fourth basic value relation beyond the standard trichotomy of 'better than', 'worse than', and equally good', what I have elsewhere called 'on a par' (Chang 2002). Indeed, it leaves open the possibility that there are many more basic relations of comparability (Rabinowicz 2008, 2012).

The point for our purposes is that parity - or some basic relation of comparability beyond the traditional trichotomy - should not be confused with incomparability. Just because two items are such that, with respect to $V$, neither is better than the other nor are they equally good, it does not necessarily follow that they are incomparable. They might be on a par. To distinguish cases of incomparability from parity, we need arguments, some of which I have given elsewhere (Chang 2002). But conceptually the two are easy to distinguish. Incomparabilty is the failure of any positive basic value relation to hold; parity is the holding of a particular basic value relation beyond the traditional trichotomy. As we'll see, the distinction between them is important for how we understand practical justification.

\section{b. Indeterminacy}

Another idea that can be easily confused with incomparability is semantic indeterminacy, in particular, vagueness. ${ }^{11}$ Incomparability holds when it is false or determinately not the case that any positive, basic, binary value relation holds between the items with respect to V. Vagueness in comparability holds when it is

11 There is also the possibility of metaphysical indeterminacy, which may be one explanation of parity, but there is no space to discuss this kind of indeterminacy here (see Chang 2000: ch. 5). 
neither true nor false, or indeterminate, that a positive, basic, binary value relation holds between the items with respect to $\mathrm{V}$.

Indeterminacy in comparison is due to the vagueness of the concepts employed in the comparison, most plausibly the covering consideration, $V$. Take a nonevaluative comparison between Herbert and Henry with respect to baldness. 'Baldness' is a vague predicate - it has indeterminate application to a range of hair profiles that, suppose, include those belonging to Herbert and Henry. Since it is indeterminate whether Herbert is bald and indeterminate whether Henry is bald, it could be indeterminate whether Henry is balder than Herbert, indeterminate whether Herbert is balder than Henry, indeterminate whether they are equally bald - one might have one more hair than the other, but the distribution of hairs might be such that they aren't determinately equally bald. The vagueness of $V$ can thus be one source of vagueness in comparability. ${ }^{12}$

In the evaluative case, comparisons might be indeterminate if the concept $V$ is vague. Take happiness, plausibly a vague term. It might be indeterminate whether Mary is happy and indeterminate whether John is happy, and thus perhaps indeterminate whether either is happier than the other or they are equally happy. It might also be indeterminate whether they are on a par with respect to happiness. If these four relations exhaust the conceptual space of comparability between two items with respect to $\mathrm{V}$, then the comparative happiness of Mary and John is indeterminate. Indeterminacy holds when it's indeterminate which comparative relation holds between them. Incomparability holds, by contrast, when it is determinately the case that no positive relation does.

Some philosophers have argued that putative cases of incomparability are in fact cases of vagueness. The most well-known argument is by John Broome (Broome 1997).

Broome's argument is too complex to summarize here, but we can examine the central principle, the 'collapsing principle', upon which the argument relies. According to the collapsing principle in its general form, "For any $\mathrm{x}$ and $\mathrm{y}$, if it is more true that $\mathrm{x}$ is F-er than $\mathrm{y}$ than that $\mathrm{y}$ is F-er than $\mathrm{x}$, then $\mathrm{x}$ is F-er than $\mathrm{y}$ " (Broome 1997: 77).

Broome's argument for the principle is as follows: ${ }^{13}$

12 This is not to say that the vagueness of $V$ entails the indeterminacy of comparability with respect to $\mathrm{V}$ as in many cases it does not. Nor is this to say that the only way indeterminacy in comparability can arise is by the vagueness of $V$. Other ways in which there could be vagueness in comparability is if there is vagueness in the comparative of $V$ or in the unrelativized comparative, such as 'better than'.

13 For a more detailed examination and critique of Broome's argument, see Chang 2002: ch 6. 
My only real argument [for the collapsing principle] is this: If it is false that $y$ is F-er than $x$, and not false that $x$ is F-er than $y$, then $x$ has a clear advantage over y in respect of its F-ness. So it must be F-er than y. It takes only the slightest asymmetry to make it the case that one thing is F-er than another. One object is heavier than another if the scales tip ever so slightly toward it (Broome 1997: 74).

The basic idea is that anything that tips the scales in favor of $x$ being F-er than $y$, including it's not being false that $\mathrm{x}$ is F-er than $\mathrm{y}$ while it's being false that $\mathrm{y}$ is F-er than $\mathrm{x}$, makes what might look like the fact that it's neither true nor false that $\mathrm{x}$ is Fer than $\mathrm{y}$ 'collapse' into the fact that it's true that $\mathrm{x}$ is F-er than $\mathrm{y}$.

But this principle has plausibility only if Fness - be it moral goodness, beauty, or justice - can be measured by cardinally significant real numbers - that is, if we have commensurability among bearers of Fness. ${ }^{14}$ If bearers of Fness are commensurable, then arguably (but only arguably) any asymmetry in favor of x's being F-er than $\mathrm{y}$ might support a collapse in favor of its being true that $\mathrm{x}$ is F-er than $\mathrm{y}$. If F-ness can be measured by cardinal units, then a slight asymmetry in favor of one comparative claim might conceivably 'tip the scales' so that the claim is true where it might have seemed neither true nor false. But if F-ness isn't representable by cardinal units, the collapsing principle has little going for it. Any consideration in favor of x's being Fer than $y$ need not translate into it's being true that $x$ is Fer than y. Since it's hard to believe that all values ('all' is needed for the argument to work) can be measured by cardinal units of value, the principle - and the more complex argument upon which it relies - can be rejected.

Thus we should insist not only that the phenomena of incomparability and of indeterminacy due to vagueness are conceptually distinct, but also that there seems to be no good reason to think that one phenomenon collapses into the other.

\section{c. Noncomparability}

Comparability and incomparability must proceed relative to some covering consideration, V. So far, we have said very little about this ' $\mathrm{V}$ ' other than that it can be a value or values which may be related in different ways. There is much to be said about which sorts of considerations can occupy the role of ' $V$ ', but we don't have space to examine those issues here. Instead, I want to point out one feature of a consideration that disqualifies it from playing the role of $\mathrm{V}$ in particular claims of comparability and incomparability. This will help us to distinguish incomparability from a related phenomenon, noncomparability.

${ }^{14}$ Indeed, Broome supposes that evaluative properties can be represented by cardinally significant real numbers in other work. See Broome 1991; 2004. 
Associated with each V is a term ' $V$ ', such as 'beauty', 'justice', 'well-being', 'utility as a corkscrew', 'tastiness' and so on. Each term has a domain of application, that is, there are certain items to which the term properly applies. So, for example, the number four and beauty, in virtue of being abstract, cannot be tasty. Abstract numbers and values, then, do not fall within the domain of application of 'tasty'. Failing to fall within the domain of application should not be confused with a term's failing to hold of an item. Abstract numbers are not the kind of thing that could be tasty. Lamps, buildings, and excrement are all things that could be tasty or not, and so they fall within the domain of application of 'tasty' - it's just false that they are.

If we tried to compare the number 4 and beauty with respect to tastiness, we would fail: no positive, basic, binary value relation holds between them with respect to tastiness. But this failure is not the substantive failure of incomparability; it is rather a formal failure of comparability, noncomparability.

If at least one of two items being compared fail to fall within the domain of the application of ' $\mathrm{V}$ ' in the context of an attempted comparison, then they are noncomparable with respect to V. ${ }^{15}$ Put another way, if the covering consideration, $\mathrm{V}$, fails to 'cover' both items being compared, they will be noncomparable. But they can be neither comparable nor incomparable since the formal prerequisites for being eligible as either comparable are incomparable have not been met. Noncomparability holds when the formal conditions required for comparability or incomparability to be possible fail to hold. Being 'covered' by the covering consideration - that is, falling within the domain of its associated term in the context of comparison - is one such formal condition. We already encountered another that there be a covering consideration with respect to which the items are compared.

Thus, if one attempts to compare rotten eggs and the number nine with respect to tastiness, they are noncomparable with respect to tastiness. But if one attempts to compare them with respect to, say, which associated idea is more pleasant to think about, perhaps the number nine is better.

Noncomparability among alternatives for choice has little philosophical significance. This is because the distinction between formal and substantive failures of comparability tracks the distinction between genuine practical choice situations and gerrymandered or ersatz ones. Practical reason will never ask agents to compare rotten eggs and the number nine with respect to tastiness - there can never be a

${ }^{15}$ For a defense of the condition that only one and not both items must fail to be covered, see Chang 1997a. I add the condition 'in the context of an attempted comparison' because, as Ralf Bader pointed out to me in conversation, it is possible that two alternatives for choice could individually bear $\mathrm{V}$ but in the context of a comparison fail to bear $\mathrm{V}$ for the purposes of that comparison. I doubt there is any non-stipulated or non-artificial $V$ that admits of this possibility, but I here leave open the possibility. 
genuine choice situation in which one must choose between alternatives with respect to some consideration that fails to 'cover' both of them in the context of comparison. ${ }^{16}$ Practical reason guarantees that once what matters in a choice is determined, the alternatives will be bearers of what matters in the choice between them in that choice situation. By contrast, incomparability poses a serious threat to practical reason. To this threat we now turn.

\section{Why Is Incomparability Important?}

According to 'comparativist' views of practical justification, the comparability of alternatives is a necessary condition for the possibility of a (objectively) justified choice between them in that choice situation (Chang 1997, forthcoming). ${ }^{17}$ The incomparability of alternatives in a choice situation is important, then, because it blocks the possibility of a justified choice between them in that choice situation.

Those who reject comparativism tend to make assumptions about comparability that comparativists need not adopt. For example, some deny that the comparability of the alternatives is required for the possibility of justified choice because they conflate comparability with commensurability. Commensurability is not required, but comparability is (see Anderson 1997). Others think that comparativism presupposes a maximizing view of justification: if the comparability of alternatives is necessary for there to be a justified choice, this must be because justification is a matter of choosing what maximizes V (Stocker 1997). But comparability does not entail maximization; perhaps a justified choice is one that is good enough with respect to $\mathrm{V}$, but being good enough relies on the comparability of the alternatives.

Although comparativism is widely accepted, arguments for it are thin on the ground. I will end this chapter by suggesting two arguments in its support. First, comparativism underwrites a deep and attractive way of connecting three basic phenomena of practical reason: values, reasons, and action. Comparativism provides a structure that holds together a wide-ranging, intuitive, and yet flexible view about how the fundamental phenomena of practical reason relate. Second, the main rival to comparativism, 'maximalism', lacks intuitive support. As I will suggest, the most plausible justification for maximalism turns on conflating practical reason with its subdomains.

a. Value, reasons, action

16 This formal condition might be considered a constraint on how we understand the values relevant to a choice situation. If one is tempted to think that a value that fails to cover an option is relevant to the choice situation, one has misunderstood the choice situation.

${ }^{17}$ By 'objective justification' I mean 'supported by most objective reason' or 'objectively rational' where the rationality is that of reasons, not mere norms such as structural norms governing movements of mind. 
Suppose you have to choose between two vacation getaways, and what matters in the choice is doing what makes your life go best. One vacation involves a solitary, rejuvenating retreat at an urban spa while the other involves camping with friends in awe-inspiring wilderness. If the spa vacation will make your life go better, then you have most reason to choose it. If the spa vacation is worse, then you have less reason to choose it, and, other things equal, most reason to choose the camping trip. Here we have a tidy isomorphism among value and reasons and action: if one alternative is better with respect to the value that matters in the choice, then you have most reason to choose it, and if it is worse in value, then you have most reason to choose the other alternative. ${ }^{18}$ If the vacations are equally good with respect to $\mathrm{V}$, then you have sufficient reason to choose either. Being better in value maps onto having most reason to choose it; being worse in value maps onto having more reason to choose something else; being equal in value maps onto having sufficient reason to choose either alternative.

But we should distinguish different ways in which you might have sufficient reason to choose either of two alternatives. Following Edna Ullman-Margalit and Sidney Morgenbesser (1977), we might say that when you have sufficient reason to choose either of two equally good alternatives, you 'pick' one. Picking is the arbitrary selection of an alternative on the basis of its value or the reasons that support it, but that value and those reasons don't support choosing it over the other alternative. We might reserve the term 'choose' for the selection of one alternative over the other on the basis of values and reasons that support selecting it over the alternatives. Thus having most reason because one alternative is better than the other justifies choosing in this strict sense; having sufficient reason because the alternatives are equally good justifies picking. Crucially, when you pick, you act within the scope of practical reason. You pick rather than choose because you have equal reason to choose either, not because your reasons are silent as to what, all things considered, you should do.

What about cases of incomparability? If the vacations are incomparable with respect to what makes your life go best, then you have neither most reason to choose nor sufficient reason to pick either. Reasons have 'run out'; they are silent on the question of whether you have most or sufficient reason to choose either alternative. Since you have neither most nor sufficient reason to select either, your selection in that choice situation cannot be within the scope of practical reason. Here we might say that you 'plump' for one of the alternatives. Plumping, like picking, is arbitrary selection, but only the latter is action within the scope of practical reason. Plumping is appropriate when reasons have run out but not when they are evenly balanced. This is because plumping - action outside the scope of practical reason - is a correct

18 The appeal to an isomorphism allows for neutrality on the priority relations that might hold among values, reasons, and action. 
response when reasons are silent on the question of what you should do, all things considered, but not when reasons tell you to pick, all things considered. ${ }^{19}$

If plumping is action outside the scope of practical reason, what kind of action is it? Perhaps plumping is an exercise of mere animal agency, as when, for example, you might plump between two meals after emerging from a long fast. You are unconcerned about taste, nutritiousness, and so on, but, like an animal acting instinctively, simply reach for the nearest sustenance. More plausibly, plumping might be an exercise of the existentialist agency that Sartre had in mind when he claimed that existence precedes essence (Sartre 2007). Selection between alternative ways of being, Sartre thought, was fundamental and not guided by reasons or values. When we plump, then, perhaps we act as existentialist agents, selecting one alternative over another in a normative void. ${ }^{20}$ If incomparability is widespread, then it seems that the existentialists were largely right: we act not as rational agents guided by reasons but as radically free creatures unmoored by reasons or values.

Finally, if comparable alternatives can be neither better nor worse than one another and not equally good, if, for example, they can be 'on a par', then there will be corresponding views about the reasons we have to act. I have suggested such a view elsewhere (see Chang 2013a). For present purposes, we should simply note that the isomorphic structure that comparativism provides among values, reasons, and action makes room for such views.

In sum, comparativism underwrites a deeply intuitive structure relating value, reasons, and action, given in the chart below.

\begin{tabular}{|l|l|l|}
\hline Value & Reasons & Action \\
\hline $\mathrm{x}$ is better than $\mathrm{y}$ & most reason to choose $\mathrm{x}$ & choose $\mathrm{x}$ \\
\hline $\mathrm{x}$ is worse than $\mathrm{y}$ & most reason to choose $\mathrm{y}$ & choose $\mathrm{y}$ \\
\hline $\mathrm{x}$ and y are equally good & $\begin{array}{l}\text { sufficient reason to } \\
\text { choose either } \mathrm{x} \text { or } \mathrm{y}\end{array}$ & pick x or pick y \\
\hline $\mathrm{x}$ and y are on a par & $? ?$ & $? ?$ \\
\hline $\mathrm{x}$ and y are incomparable & $\begin{array}{l}\text { neither most reason to } \\
\text { choose one nor sufficient } \\
\text { reason to pick either- } \\
\text { outside the scope of } \\
\text { practical reason }\end{array}$ & plump for $\mathrm{y}$ or plump for \\
\hline
\end{tabular}

\footnotetext{
19 We can leave aside the complication of alternative responses, most notably, abandoning that choice situation and moving to one that does not involve incomparable alternatives (Barcan Marcus 1980).

20 We might be able to act as quasi-existentialist agents if we plump on the basis of pro tanto reasons. This seems to be Joseph Raz's view (Raz 1997).
} 
b. Maximalism

But comparativism has an important rival, 'maximalism'. According to maximalism, in order for a choice to be justified, it need only be not worse than the other alternatives. An alternative is justified so long as it is a maximal alternative, that is, not worse than any of the others. And since being not worse is not a positive comparative relation, being maximal is compatible with being incomparable. Thus, if two items are incomparable, there is a justified choice between them. One is justified in choosing either since each alternative is not worse than the other. Maximalism is a noncomparativist view; it holds that the comparability of alternatives is not necessary for the possibility of a justified choice.

Maximalism is widely accepted by decision theorists and rational choice theorists but also, usually implicitly, by many moral philosophers (e.g. Raz 1999). It is a less stringent view of practical reason than comparativism since its standard for practical justification is significantly weaker: according to maximalism, to be justified an alternative need only be not worse than any other, while, according to comparativism, to be justified an alternative must be at least as good or comparable in some other way (e.g. on a par) with the other alternatives. Which standard should we accept?

We might look for an intuitive justification of the maximalist's key idea. A metaphor might help. Maximalism's key idea is that being not worse is sufficient for being justified. It holds, then, that so long as an alternative hasn't, as it were, been knocked out of the arena of reasons by an alternative supported by stronger reasons, it is a justified choice. This is a deeply intuitive idea and explains, I believe, why maximalism enjoys such widespread support.

This intuitive justification of maximalism, however, is one that the comparativist can also help herself to. We need to distinguish the ways in which an alternative can be 'left standing' in the arena of reasons. One way is by the alternative being equally as good as the other. This case won't distinguish comparativism from maximalism since both allow that choice can be justified when alternatives are equally good. What distinguishes maximalism from comparativism is the thought that there can be a justified choice among alternatives that are incomparable. Comparativism denies this. So we need to narrow the intuitive appeal of maximalism by asking the following: why think that a choice can be justified if it is left standing in the arena of reasons by being incomparable with the other alternatives?

Put this way, the intuitive force of maximalism is less clear. If there is no comparative relation between two alternatives, why think you are justified in choosing either? After all, with respect to what matters in the choice between them, they cannot be compared. We might say that incomparable alternatives are not ones left standing in the arena of reasons; rather, they haven't even gained entry to it. Once we clearly identify where maximalism departs from comparativism, it seems that there is no justification for the former. 
I'll end with a diagnosis for why maximalism appears to have intuitive appeal. I believe that maximalism's appeal involves conflating justification in a sub-domain of practical reason with justification in the domain of practical reason itself.

Consider legal justification. The law has limited jurisdiction over intentional actions; it does not attempt to rule on the justification of any intentional action whatever but only those that fall within its purview. There are thus two ways in which an action can be legally justified: first, by falling within the law's jurisdiction and being substantively justified and, second, by falling outside of the law's jurisdiction but not running afoul of any of its prohibitions. Actions that fall outside of the law's jurisdiction are legally justified, as it were, as a matter of default. For example, the law does not have jurisdiction on how many times a day you are to brush your teeth. So long as your teeth-brushing activities don't violate any legal prohibition, what you do, teeth-brushing-wise, is legally justified as a matter of default. The same goes for any other subdomain of practical reason. The way you wear your hair is not within the jurisdiction of the rules of chess. Thus, so long as the way you wear your hair doesn't violate any rules of chess, your stylish bob is chess-justified as a matter of default.

The possibility of being justified as a matter of default by not falling within the jurisdiction of a practical subdomain explains, I believe, why some theorists have been attracted to the idea that a justified choice is possible among incomparables. Actions that do not fall within a subdomain of reasons might be considered incomparable with respect to what matters in the choice. Brushing your teeth three times a day might be thought to be incomparable with brushing your teeth two times a day with respect to the conforming to the law. ${ }^{21}$ If they are incomparable, they are not worse than one another with respect to one's legal duties, and one is legally justified in doing either. This is the kind of case in which it is plausible to think that justified choice might be possible between incomparable alternatives.

But justification by default is not an option in the domain of practical reason itself since practical reason by its very nature has jurisdiction over all intentional actions. So an action cannot be practically justified as a matter of default. Since a case in which a justified choice among incomparables is possible within a sub-domain cannot arise within practical reason writ large, the rationale for the maximalist view according to which justified choice among incomparables is possible has no application. Comparativism, not maximalism, is thus the more plausible view of practical justification.

21 These options are not noncomparable with respect to one's legal duties because they are actions that could in principle fall afoul of the law if, for example, you are a toothpaste model who owes your employer a duty to brush your teeth more than twice a day. 


\section{REFERENCES}

Adler, Matthew. This volume. 'Value and Cost-Benefit Analysis'.

Anderson, Elizabeth. 1997. "Practical Reason and Incommensurable Goods." In Chang, ed.

Anderson, Elizabeth. 1993. Value in Ethics and Economics. Cambridge, MA: Harvard University Press.

Andreou, Chrisoula. Draft. 'Parity, Comparability, and Choice'.

Bader, Ralf. This volume. 'Kantian Axiology and the Dualism of Practical Reason'.

Barcan Marcus, Ruth. 1980. 'Moral Dilemmas and Consistency.' Journal of Philosophy 77 (3): 121-136.

Broome, John. 2004. 'Reasons.' In Reason and Value: Themes from the Moral Philosophy of Joseph Raz. Oxford: Oxford University Press, pp. 28-55.

Broome, John. 1991. Weighing Goods. Oxford: Blackwell.

Broome, John. 1997. 'Is Incommensurability Vagueness?' In Chang, ed.

Carlson, Erik. This volume. 'Organic Unities'.

Chang, Ruth. Forthcoming. 'Comparativism: In Defense of Weighing Reasons.' In Weighing Reasons, eds., Barry McGuire and Errol Lord. Oxford University Press, in press.

Chang, Ruth. 2013a. 'Commitments, Reasons, and the Will', in Shafer-Landau, ed., Oxford Studies in Metaethics, vol. 8, pp. 74-113, 2013.

Chang, Ruth. 2013b. 'Grounding Practical Normativity: Going Hybrid', Philosophical Studies 164 (1): 163-187.

Chang, Ruth. 2013c. 'Are Hard Choices Cases of Incomparability?', Philosophical Issues, vol., 22, no. 1, pp. 106-126, 2012.

Chang, Ruth. 2009a. 'Voluntarist Reasons and the Sources of Normativity', Reasons for Action eds., Sobel and Wall, (New York: Cambridge University Press, 2009), pp. 243-71. 
Chang, Ruth. 2009b. 'Incommensurability (and Incomparability)', International Encyclopedia of Ethics, Blackwell 2009, series editor, Hugh La Follette.

Chang, Ruth. 2004a. 'Putting Together Morality and Well-Being' in Practical Conflicts, eds. M. Betzler and P. Baumann. Cambridge: Cambridge University Press, pp. 118-58.

Chang, Ruth. 2004b. 'All Things Considered.' Philosophical Perspectives 18: 1-22.

Chang, Ruth. 2002. 'The Possibility of Parity'. Ethics 112: 659-688.

Chang, Ruth. 2000. Making Comparisons Count. New York: Routledge.

Chang, Ruth. 1997a. 'Introduction.' In ed., Chang 1997, pp. 1-34.

Chang, Ruth. 1997b. Ed. Incommensurability, Incomparability and Practical Reason. Cambridge: Harvard University Press.

Copp, David. 1997. 'The Ring of Gyges: Overridingness and the Unity of Reason.' Social Philosophy and Policy 14: 86-106.

D'Agostino, Fred. 2003. Incommensurability and Commensuration: The Common Denominator. Burlington, VT: Ashgate Press.

Elson, Luke. Forthcoming. 'Heaps and Chains: Is the Chaining Argument for Parity a Sorites?'. Ethics.

Foot, Philippa. 1978. 'Morality as a System of Hypothetical Imperatives.' In her Virtues and Vices. Oxford: Blackwell, pp. 157-173.

von Fritz, Kurt. 1971. "The Discovery of Incommensurability by Hippasus of Metapontum". In David Furley and R.E. Allen, eds., Studies in Presocratic Philosophy. (London: Routledge).

Froding, Barbara and Martin Peterson. 2012. 'Virtuous Choice and Parity.' Ethical Theory and Moral Practice 15(1): 71-82.

Griffin, James. 1986. Well-Being. Oxford: Clarendon Press.

Hart, H.L.A. 1961. The Concept of Law. Oxford: Clarendon Press.

Heath, Thomas. 1921. A History of Greek Mathematics. Oxford: Clarendon Press.

Hsieh, Nien-hê. 2008.'Incommensurable Values.' The Stanford Encyclopedia of Philosophy, ed. Edward N. Zalta, URL = <http://plato.stanford.edu/archives/fall2008/entries/value-incommensurable/>. 
Hsieh, Nien- hê. 2005. 'Equality, Clumpiness and Incomparability.' Utilitas 17 (2): 180-204.

Hurka, Thomas. 1993. Perfectionism. Oxford: Oxford University Press.

Nagel, Thomas. 1979. 'The Fragmentation of Value.' In his Mortal Questions. New York: Cambridge University Press, pp. 128-141.

Parfit, Derek. 1986. Reasons and Persons. Oxford: Oxford University Press.

Parfit, Derek. Draft. Toward Theory X.

Rabinowicz, Wlodek. 2008. 'Value Relations.' Theoria 74: 18-41.

Rabinowicz, Wlodek. 2012. 'Value Relations Revisited.' Economics and Philosophy 28(2): 133-164.

Raz, Joseph. 1986. The Morality of Freedom. Oxford: Clarendon Press.

Raz, Joseph. 1999. Engaging Reason. Oxford: Clarendon Press.

Richardson, Henry. 1994. Practical Reasoning about Final Ends. Cambridge:

Cambridge University Press.

Richardson, Henry. 2000. 'The Stupidity of the Cost-Benefit Standard.' The Journal of Legal Studies 29 (2): 971-1003.

Ronnow-Rasmussen, Toni. 2011. Personal Value. Oxford: Oxford University Press.

Sartre, Jean-Paul. 2007. Existentialism is a Humanism. New Haven: Yale University Press.

Scanlon, Thomas. 1998. What We Owe to Each Other. Cambridge, MA: Belknap Press.

Schmidtz, David. This volume. 'Value in Nature.'

Sinnott-Armstrong, Walter. 1988. Moral Dilemmas. Oxford: Blackwell.

de Sousa, Ronald. 1974. 'The Good and the True.' Mind 83: 534-551.

Stocker, Michael. 1997. 'Abstract and Concrete Value: Plurality, Conflict, and Maximization.' In Chang, ed., pp. 196-214.

Ullman-Margalit, Edna and Sidney Morgenbesser. 1977. 'Picking and Choosing.' Social Research 44:757-787. 
Williams, Bernard. 1981. 'Conflicts of Values.' In his Moral Luck. Cambridge: Cambridge University Press, pp. 71-82.

Zimmerman, Michael. This volume. 'Value and Normativity'. 